\title{
The Role of Lateral Internal Sphincterotomy in Haemorrhoidectomy: A Study in a Tertiary Care Center
}

\author{
Shashikanth Vijayaraghavalu ${ }^{1}$, Guru Prasad R ${ }^{2}$, Sathish Rajkumar ${ }^{1}$ \\ 1. General Surgery, ACS Medical College Hospital, Chennai, IND 2. General Surgery/Surgical Oncology, ACS Medical \\ College Hospital, Chennai, IND
}

Corresponding author: Shashikanth Vijayaraghavalu, shashibabloooo@gmail.com

\section{Abstract \\ Background}

Hemorrhoids are a common condition that presents with bleeding per rectum, pain at rest and defecation, mucosal discharge, and prolapse. Surgical hemorrhoidectomy is the treatment method of choice for Grade 3 and Grade 4 hemorrhoids. Hemorrhoidectomy is associated with postoperative pain and no single surgical technique has been proved to significantly reduce the pain. We analyzed in our study the effect of lateral internal sphincterotomy with hemorrhoidectomy on postoperative pain, anorectal function, and retention of urine after the Milligan and Morgan technique.

\section{Methods}

This randomized, prospective, and comparative study included 200 Grade 3 and Grade 4 hemorrhoids patients who were scheduled for surgical management. The patients were classified randomly into two groups with an equal number of participants: Group A underwent Milligan \& Morgan open

hemorrhoidectomy and Group B underwent lateral internal sphincterotomy (LIS) in addition to Milligan and Morgan open hemorrhoidectomy. Postoperative pain was recorded using the Visual Analog Scale (VAS) score for up to 48 hours. Postoperative bleeding, urinary retention, and bowel and gas incontinence were noted. Long-term follow-up at six and 24 months for anal stenosis, anal fissure, incontinence, and recurrence was also noted.

\section{Results}

Patients who underwent LIS showed a significant reduction in postoperative pain at 12 hours $\left(\mathrm{p}=0.0008^{*}\right), 24$ hours $\left(\mathrm{p}=0.000^{*}\right)$, and 48 hours $\left(\mathrm{p}=0.003^{*}\right)$; the time taken to request rescue analgesia was similar between the two groups $(\mathrm{p}=0.07$ ). Side effects, such as postoperative bleeding and urinary retention, were significantly lower after LIS ( $\mathrm{p}=0.001^{*}$ and $\mathrm{p}=0.01^{*}$, respectively), and gas incontinence was significantly higher after LIS $\left(\mathrm{p}=0.002^{*}\right)$. The long-term outcomes of anal fissure were significantly higher without LIS at six months $(\mathrm{p}=0.02 *)$ and 24 months $\left(\mathrm{p}=0.04^{*}\right)$ and those of anal stenosis were significantly higher without LIS at six months $\left(\mathrm{p}=0.04^{*}\right)$.

Review began 05/31/2021 Review ended 06/04/2021 Published 06/13/2021

\section{(c) Copyright 2021}

Vijayaraghavalu et al. This is an open access article distributed under the terms of the Creative Commons Attribution License CC-BY 4.0., which permits unrestricted use, distribution, and reproduction in any medium, provided the original author and source are credited.

\section{Conclusions}

From our study, we conclude that postoperative pain, bleeding, and urinary retention were significantly lower after LIS, and gas incontinence was transient. The long-term outcomes, which included anal stenosis and anal fissure, were significantly lower after LIS. However, bowel and gas incontinence and recurrence were not altered. Therefore, we conclude that the addition of LIS to hemorrhoidectomy improves patient outcomes in terms of postoperative pain and anorectal function.

Categories: General Surgery

Keywords: lateral internal sphincterotomy, hemorrhoids, haemorrhoidectomy, incontinence, anal stenosis, anal fissure

\section{Introduction}

Hemorrhoids are formed by the downward displacement of dilated submucosal vascular anal cushions, commonly located at 3,7 , and 11 o'clock in the anal canal. It is a common condition which presents with complaints of bleeding per rectum, pain at rest and defecation, mucosal discharge, and prolapse. Surgical hemorrhoidectomy is the treatment method of choice for Grade 3 and Grade 4 hemorrhoids [1,2].

The surgical techniques employed include the Milligan and Morgan technique, which is most commonly performed, the Ferguson technique, stapled hemorrhoidectomy, the technique using a harmonic scalpel or ligasure, and Doppler-guided hemorrhoidal artery ligation. The early complications after surgery include postoperative pain, primary hemorrhage, and retention of urine [3]. 
Hemorrhoidectomy is associated with postoperative pain, and no single surgical technique has been proved to significantly reduce the pain [4]. The pain following hemorrhoidectomy may be due to anal packing, urinary retention, wound edema, or increased tone due to spasm of the internal sphincter [5]. Various invasive and non-invasive techniques have been employed to relieve the spasm such as topical nitroglycerin (NTG), calcium channel blocker (CCB), Lord's dilatation, and lateral sphincterotomy. Each of these measures has its side effects.

We analyzed in our study the effect of lateral internal sphincterotomy with Milligan and Morgan hemorrhoidectomy on postoperative pain, anorectal function, and retention of urine.

\section{Materials And Methods}

This randomized prospective comparative study was performed in ACS Medical College Hospital after obtaining institutional ethical committee clearance. The following patients were enrolled in the study: patients with clinical and investigatory support for the diagnosis and willingness for the surgical management of Grade 3 and 4 hemorrhoids. Any patient with the following was excluded from the study: inflammatory bowel disease, fissure, recurrent hemorrhoids, fistula, malignancy, cirrhosis, and portal hypertension, pregnancy, and age $<20$ and $>60$ years. All patients enrolled in the study were explained about the study procedure and their informed written consent was taken. The study comprised 200 patients of Grade 3 and 4 hemorrhoids who were randomly divided into two groups of 100 each, named Group A and Group B. In Group A, only Milligan and Morgan open hemorrhoidectomy was done, and in Group B, lateral internal sphincterotomy (LIS) was done in addition to Milligan and Morgan open hemorrhoidectomy.

Preoperatively, patients in both groups were optimized. Patients in both groups were started on metronidazole therapy for five days, along with oral liquid paraffin. All patients in the study were prescribed local application of glycerine and magnesium sulfate soaked dressings to reduce edema and relieve pain. Patients were also advised to take a Sitz bath thrice a day and were taught to maintain proper anal hygiene. All patients were given an enema early morning on the day of surgery. Patients in both groups received spinal anesthesia.

After spinal anesthesia, and after the optimal level of block was achieved, the patients were put in lithotomy position, parts painted, and draped. A per rectal examination and preliminary proctoscopy were done. The anal skin was held with Allis forceps and retracted first at the 7 o'clock position. The hemorrhoidal mass was visualized and held with artery forceps. A V-shaped incision was made at the skin from the anoderm up to the anal mucosa, followed by gentle dissection. The hemorrhoid mass was separated from the internal anal sphincter till the apex of the pedicle was reached. The hemorrhoid pedicle was ligated using vicryl (absorbable suture) and excised in toto. The bare area was left open. A similar procedure was repeated first at 3 o'clock position, and finally at the 11 o'clock position. Complete hemostasis was obtained. An anal pack was kept which was soaked in liquid paraffin and povidone-iodine.

For those in Group B, in addition to the Milligan and Morgan technique, a lateral internal sphincterotomy was also done. Intersphincteric groove was palpated. A $1 \mathrm{~cm}$ lateral incision made at 3 o'clock position near the anal verge. Gentle dissection was done along the submucosa till the internal sphincter was reached. The lower free end of the internal sphincter was hooked out using artery forceps and divided. Complete hemostasis was obtained and the wound was left open. The intraoperative bleeding during the surgery was kept to a minimum using cautery and gentle dissection.

Postoperatively, all the patients were kept nil per oral for six hours after surgery and later started on a liquid diet, followed by a soft, high-fiber diet. All the patients in Group A and Group B were routinely given injection paracetamol $1 \mathrm{~g}$ intravenously (IV) on the night of surgery. If the patients complained of pain prior to this, then injection tramadol $100 \mathrm{mg}$ IV was given as rescue analgesia. The anal pack was removed in both groups after six hours postoperatively. The patients were also advised on the need for early ambulation and a sitz bath postoperatively to minimize the chances of infection.

The primary objective of the study was pain relief after surgery in the postoperative period. The pain was assessed by using the Visual Analog Scale (VAS) at 12, 24, and 48 hours with a rating ranging from 0-10: 0 no pain, 1-3 - mild pain, 4-6 - moderate pain, 7-10 - severe pain. The time taken for the first request of rescue analgesia was also noted. The secondary objective included postoperative complications. Factors taken into account included postoperative incidence of bleeding, urinary retention, and bowel and gas incontinence until 48 hours.

The observation and data collection of bleeding was assessed subjectively into groups based on the amount of bleeding. They were grouped as: None - no bleeding; Confined - minimal loss/occasional episodes during defecation (<20 ml of blood); Moderate - frequent episodes during defecation ( $>20 \mathrm{ml}$ of blood); Severe persistent bleeding even without defecation with fall in hemoglobin levels $(<10 \mathrm{~g} / \mathrm{dl}$ requiring hematinics or $<7 \mathrm{~g} / \mathrm{dl}$ requiring blood transfusion).

Both the groups were observed for the inability to void urine under voluntary control. For those who failed to 


\section{Cureus}

void voluntarily, bladder catheterization was done. Percentage of patients who required bladder catheterization for urine drainage was noted. Incontinence was assessed by Wexner's incontinence score for solid, liquid, and gas. Short-term and long-term follow-ups were done at six and 24 months after surgery to rule out late complications like anal fissure, anal stenosis, bowel or gas incontinence, and recurrence.

\section{Statistics}

Data were analyzed using the Statistical Package for Social Sciences (SPSS); continuous variables were analyzed using unpaired t-test for two means, and categorical data were analyzed using Chi-square test. Data were expressed as mean \pm SD and as percentages where appropriate. P-value $<0.05$ was considered statistically significant.

\section{Results}

In the present study, both groups were comparable in terms of age, weight, sex, and grade of disease (Table 1).

\begin{tabular}{|c|c|c|c|c|}
\hline & Age $($ mean $\pm S D)$ & Weight (mean \pm SD) & Sex (no. of cases) & Grade of disease $3 / 4$ (no. of cases) \\
\hline Group a & $42.15 \pm 12.4$ & $77.73 \pm 6.9$ & $M(60) f(40)$ & $46 / 54$ \\
\hline Group b & $41.03 \pm 10.9$ & $76.83 \pm 6.2$ & $M(60) f(40)$ & $42 / 58$ \\
\hline P-value (two-sample t-test) & 0.49 (ns) & 0.33 (ns) & $\begin{array}{lll}- & \end{array}$ & 0.52 (ns) \\
\hline
\end{tabular}

TABLE 1: Demographic data of patients in the two study groups

The VAS score was assessed at 12 hours, 24 hours, and 48 hours postoperatively. The mean VAS score in Group A was 6.12 at 12 hours, 5.61 at 24 hours, and 4.04 at 48 hours. The Mean VAS score in Group B was 5.1 at 12 hours, 3.4 at 24 hours, and 3.2 at 48 hours. The VAS score was statistically significant at 12, 24, and 48 hours. The p-values were $0.0008 *$ (12 hours), $0.000 *$ (24 hours), $0.003 *$ (48 hours) (Table 2 ). The mean time taken for the first requirement for rescue analgesia in Group A was 191.6 mins, and in Group B, it was 189.7 mins, which were not statistically significant. The p-value was 0.07 (ns) (Table 2).

\begin{tabular}{|c|c|c|c|}
\hline VAS score post-operatively & Group A (mean $\pm S D)$ & Group B (mean $\pm S D)$ & P-value (two-sample t-test) \\
\hline 12 hours & $6.12 \pm 2.3$ & $5.1 \pm 1.9$ & $0.0008^{*}$ \\
\hline 24 hours & $5.61 \pm 1.2$ & $3.4 \pm 1.1$ & $0.000^{*}$ \\
\hline 48 hours & $4.04 \pm 1.1$ & $3.2 \pm 2.5$ & $0.003^{\star}$ \\
\hline Time taken for the first request of rescue analgesia & $191.6 \pm 1.58$ & $189.7 \pm 10.5$ & $0.07(\mathrm{~ns})$ \\
\hline
\end{tabular}

\section{TABLE 2: Postoperative VAS scores and rescue analgesia requirement}

* significant; ns: not significant; VAS: Visual Analog Scale

Postoperative bleeding in Group A was confined in 76 patients and moderate bleeding occurred in 14 patients. In Group B, confined bleeding occurred in 72 patients and moderate bleeding in three patients. None of the study patients had severe bleeding. Ten patients in Group A had no bleeding, and 25 patients in Group B had no bleeding. The incidence of postoperative bleeding was statistically significant between the groups $(\mathrm{p}$-value $=0.001$ *) (Table 3). Urinary retention requiring catheterization was seen in 17 patients in Group A and six patients in Group B, which was statistically significant ( $\mathrm{p}=0.01^{*}$ ) (Table 3). Gas incontinence occurred in 9 patients in group B and none in group A which was statistically significant $(\mathrm{p}=0.002 *)$ (Table

3). None of our patients had bowel incontinence in the immediate postoperative period. 


\section{Cureus}

\begin{tabular}{|c|c|c|c|}
\hline Postoperative complications & Group A ( $n=100)$ (no. of cases) & Group B ( $n=100)$ (no. of cases) & P-value (Chi-square test) \\
\hline Bleeding: None & 10 & 25 & \multirow{4}{*}{$0.001^{x}$} \\
\hline Confined & 76 & 72 & \\
\hline Moderate & 14 & 3 & \\
\hline Severe & 0 & 0 & \\
\hline Urinary Retention requiring catheterization & 17 & 6 & $0.01^{*}$ \\
\hline Bowel incontinence & 0 & 0 & - \\
\hline Gas incontinence & 0 & 9 & $0.002^{\star}$ \\
\hline
\end{tabular}

\section{TABLE 3: Postoperative complications in both groups}

* significant

Follow-up of our patients was done at six months. Of the 200 study patients, 186 patients were followed up: 92 in Group A and 94 in Group B. Five patients had an anal fissure and four had anal stenosis in Group A. In Group B, none had an anal fissure or anal stenosis. This was statistically significant with $\mathrm{p}=0.02^{*}$ and $0.04^{*}$, respectively (Table 4). No patient had a recurrence at six months in both groups. Two patients in Group B had gas incontinence and one had bowel incontinence at six months, which was not statistically significant - p-values 0.15 (ns) and $0.32(\mathrm{~ns})$, respectively (Table 4).

\begin{tabular}{|c|c|c|c|c|c|c|}
\hline & After 6 months & & & After 24 months & & \\
\hline & $\begin{array}{l}\text { Group } A(n=92) \\
\text { patients }(\%)\end{array}$ & $\begin{array}{l}\text { Group B }(\mathrm{n}=94) \\
\text { patients }(\%)\end{array}$ & $\begin{array}{l}\text { P-value (Chi- } \\
\text { square test) }\end{array}$ & $\begin{array}{l}\text { Group A }(\mathrm{n}=81) \\
\text { patients }(\%)\end{array}$ & $\begin{array}{l}\text { Group B }(\mathrm{n}=77) \\
\text { patients (\%) }\end{array}$ & $\begin{array}{l}\text { P-value (Chi- } \\
\text { square test) }\end{array}$ \\
\hline Anal fissure & $5(5.4 \%)$ & 0 & $0.02^{\star}$ & $4(4.9 \%)$ & 0 & $0.04^{\star}$ \\
\hline Anal Stenosis & $4(4.3 \%)$ & 0 & $0.04^{*}$ & $3(3.7 \%)$ & 0 & 0.08(ns) \\
\hline $\begin{array}{l}\text { Bowel } \\
\text { incontinence }\end{array}$ & 0 & $1(1.06 \%)$ & $0.32(\mathrm{~ns})$ & 0 & 0 & - \\
\hline $\begin{array}{l}\text { Gas } \\
\text { incontinence }\end{array}$ & 0 & $2(2.12 \%)$ & $0.15(\mathrm{~ns})$ & 0 & 0 & - \\
\hline Recurrence & 0 & 0 & - & $6(7.4 \%)$ & $2(2.5 \%)$ & $0.16(\mathrm{~ns})$ \\
\hline
\end{tabular}

\section{TABLE 4: Follow-up of patients at six months and 24 months}

* significant; ns: not significant

A long-term follow-up at 24 months was done. Of the 200 patients, 158 patients were followed up: 81 in Group A and 77 in Group B. Four patients had an anal fissure in Group A and none in Group B, which was statistically significant $\mathrm{p}=0.04$ * (Table 4). Three patients had anal stenosis in Group A, in Group B, none had anal stenosis, $\mathrm{p}=0.08$ (ns) (Table 4). Six patients in Group A and two in Group B had recurrence, which was not statistically significant, $\mathrm{p}=0.16$ (ns) (Table 4). None of the patients had bowel or gas incontinence at 24 months.

\section{Discussion}

Postoperative pain after haemorrhoidectomy is attributed to high anal canal pressure due to increased tone of the internal sphincter. Eisenhammer was the first to discover that spasm of internal sphincter is responsible for post-haemorrhoidectomy pain [6]. The hypothesis of haemorrhoidectomy with lateral internal sphincterotomy reducing postoperative pain is still controversial. Several studies have compared the postoperative outcomes of haemorrhoidectomy alone and haemorrhoidectomy with lateral internal sphincterotomy. 
Kanellos et al. in their study of 78 patients with Grade 4 hemorrhoids showed a statistical difference in pain scores after first defecation and one week after surgery [4]. The immediate pain scores at 12 hours were not significantly different between the groups. Diana et al. in their study with 699 patients reported postoperative pain in 192 patients, and it was the most frequent postoperative complication - $23.03 \%$ - and the number of patients who had postoperative pain decreased significantly when lateral internal sphincterotomy was done, going down from $28.8 \%$ to $10.45 \%$. They concluded that there was significant pain reduction only in the first postoperative period and not on medium- long-term follow-up [7].

In our study, the mean pain scores at 12,24 , and 48 hours were significantly lower in the group that underwent LIS in addition to haemorrhoidectomy. This is contrary to a study by Khubchandani who reported no statistical difference in postoperative pain, but this was attributed to performing LIS distal to the dentate line, terminating at the inter-sphincteric groove [8].

The time taken for the first request of analgesia was similar in both groups and did not show a statistical difference - similar to the study by Khubchandani [8]. Galizia et al. in their randomized study found a significant difference in pain scores and analgesic requirement between the two groups. However, they suggested that it was justifiable only when preoperative anorectal manometry showed high anal pressure [9].

The incidence of postoperative bleeding in our study was significantly lower in patients with LIS, whereas, among patients without LIS, 14 complained of moderate bleeding. The addition of LIS had no increased incidence of postoperative bleeding. This could be attributed to reduced straining during defecation due to relaxed anal tone and reduced spasm. Postoperative bleeding may cause anemia very rapidly in some patients. None of our patients experienced any adverse effects related to bleeding. Postoperative bleeding may be due to lack of thrombus or its expulsion or dissociation, and reabsorption of the transfixed stitch. Depending on the study considered, postoperative bleeding frequency varied between $0.6 \%$ and $10 \%$ [10,11].

Urinary retention incidence in the postoperative period requiring catheterization in our study was $17 \%$ in patients with haemorrhoidectomy and $6 \%$ in patients with LIS and haemorrhoidectomy. Toyonaga et al. [12] in their study reported an incidence of $21.9 \%$.

Postoperatively, patients having LIS may have a significantly increased risk of incontinence as suggested by some authors. Studies have also shown that sphincterotomy is accompanied by a low incidence of transient incontinence $[13,14]$. In our study, nine patients who underwent LIS had gas incontinence in the immediate postoperative period. None of our patients had bowel incontinence in the immediate postoperative period irrespective of the surgery performed.

We followed up our patients at six months and 24 months for anal fissure, anal stenosis, and bowel and gas incontinence. Patients developing anal stenosis usually have complaints of either anal pain, constipation, or bleeding $[15,16]$. Anal stenosis is believed to be reduced in LIS, whereas it is a rare serious complication of haemorrhoidectomy. The majority of studies reported no anal stenosis after LIS; since LIS shows a preventive role against stenosis, its routine inclusion with haemorrhoidectomy may be justified [17,18]. In our study, five patients and four patients who did not undergo LIS developed anal fissure at six and 24 months, respectively. Four and three patients had anal stenosis at six and 24 months, respectively - this may be due to increased anal tone caused by healing and fibrosis. Two patients who underwent LIS complained of gas incontinence and one patient complained of bowel incontinence.

Haemorrhoidal recurrence occurs in around 2-8\% of patients post-surgery [19]. Earlier, the incidence was around $14 \%$, as mentioned by Goligher in their study [20]. In our study, at 24-month follow-up, eight patients had complaints of recurrence, predominantly at the primary site. The incidence was higher in patients who underwent only open haemorrhoidectomy without LIS (7.4\%) and was significantly lower in patients with LIS (2.5\%).

\section{Conclusions}

From our study, we conclude that postoperative pain, bleeding, and urinary retention were significantly lower after LIS, and gas incontinence was transient. The long-term outcomes, which included anal stenosis and anal fissure, were significantly lower after LIS. However, bowel and gas incontinence and recurrence were not altered. Therefore, we conclude that the addition of LIS to hemorrhoidectomy improves patient outcomes in terms of postoperative pain and anorectal function.

\section{Additional Information \\ Disclosures}

Human subjects: Consent was obtained or waived by all participants in this study. ACS Medical College Hospital issued approval ACS-MCH/19/MAY/18/04. Animal subjects: All authors have confirmed that this study did not involve animal subjects or tissue. Conflicts of interest: In compliance with the ICMJE uniform disclosure form, all authors declare the following: Payment/services info: All authors have declared that no financial support was received from any organization for the submitted work. Financial relationships: All 
authors have declared that they have no financial relationships at present or within the previous three years with any organizations that might have an interest in the submitted work. Other relationships: All authors have declared that there are no other relationships or activities that could appear to have influenced the submitted work.

\section{References}

1. Taha SA: Routine internal sphincterotomy with hemorrhoidectomy for third and fourth degree hemorrhoids greatly improves the outcome. Iraq J Gastroenterol. 2003, 4:48-51.

2. Hosseini SV, Sharifi K, Ahmadfard A, Mosallaei M, Pourahmad S, Bolandparvaz S: Role of internal sphincterotomy in the treatment of hemorrhoids: a randomized clinical trial. Arch Iranian Med. 2007, 10:504-8.

3. Allen-Mersh TG, Mann CV: Open haemorrhoidectomy (St Mark's ligation/excision method). Rob and Smith's Operative Surgery: Surgery of the Colon, Rectum \& Anus, Fifth Edition. Fielding LP, Goldberg SM, Rob C (ed): Butterworth-Heinemann, Oxford; 1993. 789-96.

4. Kanellos I, Zacharakis E, Christoforidis E, Angelopoulos S, Kanellos D, Pramateftakis MG, Betsis D: Usefulness of lateral internal sphincterotomy in reducing postoperative pain after open hemorrhoidectomy . World J Surg. 2005, 29:464-8. 10.1007/s00268-004-7432-2

5. DiBella F, Esteinne G: Indications for internal medioposterior with anoplasty of lateral sphincterotomy during hemorrhoidectomy: our experience. Minerva Chirurgica . 1990 Mar, 45:361-3.

6. Eisenhammer S: Internal anal sphincterotomy plus free dilatation versus anal stretch with special criticism of the anal stretch procedure for hemorrhoids: the recommended modern approach to hemorrhoid treatment. Dis Colon Rectum. 1974, 17:493-522. 10.1007/BF02587027

7. Diana G, Guercio G, Cudia B, Ricotta C: Internal sphincterotomy reduces postoperative pain after Milligan Morgan haemorrhoidectomy. BMC Surg. 2009, 9:16. 10.1186/1471-2482-9-16

8. Khubchandani IT: Internal sphincterotomy with hemorrhoidectomy does not relieve pain: a prospective, randomized study. Dis Colon Rectum. 2002, 45:1452-7. 10.1007/s10350-004-6450-3

9. Galizia G, Lieto E, Imperatore V, Pelosio L, Castellano P: The usefulness of lateral internal sphincterotomy combined with hemorrhoidectomy in the treatment of hemorrhoids: a randomized prospective study. G Chir . 2000, 21:127-34.

10. Chik B, Law WL, Choi HK: Urinary retention after haemorrhoidectomy: Impact of stapled haemorrhoidectomy. Asian J Surg. 2006, 29:233-7. 10.1016/S1015-9584(09)60094-4

11. Pescatori M: Closed vs. open hemorrhoidectomy: associated sphincterotomy and postoperative bleeding. Dis Colon Rectum. 2000, 43:1174-5. 10.1007/BF02236571

12. Toyonaga $\mathrm{T}$, Matsushima $\mathrm{M}$, Sogawa $\mathrm{N}$, et al.: Postoperative urinary retention after surgery for benign anorectal disease: potential risk factors and strategy for prevention. Int J Colorectal Dis. 2006, 21:676-82. 10.1007/s00384-005-0077-2

13. Leong AF, Husain MJ, Seow-Choen F, Goh HS: Performing internal sphincterotomy with other anorectal procedures. Dis Colon Rectum. 1994, 37:1130-2. 10.1007/BF02049816

14. Hananel N, Gordon PH: Lateral internal sphincterotomy for fissure-in-ano--revisited. Dis Colon Rectum. 1997, 40:597-602. 10.1007/BF02055386

15. Wang WG, Lu WZ, Yang CM, et al.: Effect of lateral internal sphincterotomy in patients undergoing excisional hemorrhoidectomy. Medicine (Baltimore). 2018 Aug, 97:e11820. 10.1097/MD.0000000000011820

16. Liberman H, Thorson AG: Anal stenosis. Am J Surge. 2000, 179;:325-9. 10.1016/S0002-9610(00)00344-5

17. Shawki S, Costedio M: Anal fissure and stenosis. Gastroenterol Clin North Am. 2013, 42:729-58. 10.1016/j.gtc.2013.09.007

18. Puia IC, Bodea R, Neagoe RM: Hemorrhoidectomy and anal stenosis. J Gastrointestin Liver Dis. 2015, 24:395-6.

19. Gravié JF, Lehur PA, Huten N, et al.: Stapled hemorrhoidopexy versus milligan-morgan hemorrhoidectomy: a prospective, randomized, multicenter trial with 2-year postoperative follow up. Ann Surg. 2005, 242:29-35. 10.1097/01.sla.0000169570.64579.31

20. Goligher JC: Surgery of the Anus, Rectum and Colon, 5th Edition . Baillière-Tindall, London; 1984. 